\title{
A Micro-morphological Model for Hydrophobicity on the Locust wing
}

\author{
Gang Sun \\ School of Life Science \\ Changchun Normal University \\ Changchun, Jilin Province, P. R. China \\ E-mail: sungang@nenu.edu.cn
}

\author{
Yan Fang* \\ School of Life Science \\ Changchun Normal University \\ Changchun, Jilin Province, P. R. China \\ E-mail: fangyan124@aliyun.com \\ * Corresponding Author
}

\begin{abstract}
The hydrophobicity, chemical composition and microstructure of locust wing are investigated by a videobased contact angle (CA) meter, a Fourier transform infrared spectrometer (FT-IR) and a scanning electron microscope (SEM). A micro-morphological model for hydrophobicity of wing surface is established on the basis of Cassie equation. The wetting mechanism is discussed from the perspective of biological coupling. The results show that the locust wing is covered with a waxy layer composed mainly of long chain hydrocarbon, tallate and fatty-acid alcohol. The wing surface displays multipledimensional microstructures induding primary structure (wing vein grids), secondary structure (regularly arraying micrometric pillar gibbosities), and tertiary structure (nano corrugations). The diameter, height, and spacing of pillar gibbosity are 3.6 9.5 $\mu \mathrm{m}, 4.1 \sim 8.6 \mu \mathrm{m}$, and 7.2 14.3 $\mu \mathrm{m}$, respectively. Locust wing surface is a natural biosurface with superhydrophobicity (water contact angle $151.3 \sim 158.6^{\circ}$ ). The superhydrophobic property of locust wing surface ascribes to cooperative effect of hydrophobic material and hierarchical rough microstructure. Locust wing can be potentially used as a biomimetic template for design of special functional surface. This work may bring interesting insights for preparation of micro-controllable superhydrophobic surface.
\end{abstract}

Keywords-Locust wing; Superhydrophobicity; Micromorphology; Biomimetic; Biological coupling.

\section{INTRODUCTION}

The inter facial material with special properties and functions is attracting more and more attention due to valuable theoretical importance and application potential in industrial and domestic fields[1]. After millions of years of natural selection, many animals and plants have evolved distinctive body surfaces which are hydrophobic, self-cleaning, anti-adhesive, anti-corrosive, anti-icing, drag reducing, self-healing, fatigue resistant, and antiwearing[2-4]. Insect is the unique flying invertebrate, whose wing surface is one of the most complicated three-dimensional periodical substrates in nature[5]. Insect wing has become a biomimetic fabrication template because of its excellent characteristics such as attractive iridescence, superhydrophobic performance, and quick heat dissipation ability. Locust is a typical flying insect. Some works have been done on microstructure and wettability of insect wing surface[69], in this work, the chemical composition, microstructure and hydrophobicity of locust wing surface are investigated. Also, a micro-morphological model is established for hydrophobicity of locust wing surface on the basis of Cassie equation, and discussed the wetting mechanism from the perspective of biological coupling. The results may bring interesting insights into biomimetic design of micro-controllable superhydrophobic surface and fabrication of novel selfcleaning material.

\section{MATERIALS AND METHODS}

\section{A. Materials}

Locust specimens of five species (Celes skalo zubovi, Calliptamus abbreviatus, Acrida chinensis, Haplotropis brunneriana, Chorthippus hammarstroemi) were collected in Changchun City, Jilin Province, China from August to September 2014. The fore and hind wings were cleaned, desiccated and flattened, then cut into pieces with the size of $5 \mathrm{~mm} \times 5 \mathrm{~mm}$. The distilled water for measurements of $\mathrm{CA}$ is purchased from Tianjin Pharmaceuticals Group Co. Ltd., China. The volume of water droplets is $5 \mu \mathrm{l}$.

\section{B. Methods}

After gold coating by an ion sputter coater (Hitachi E-1045, Japan), the wing pieces were observed and photographed by a SEM (Hitachi SU8010, Japan). A video-based CA measuring system (DataPhysics OCA20, Germany) is used to measure the CA of water droplet on the wing surface by sessile drop method at ambient temperature of $(25 \pm 1){ }^{\circ} \mathrm{C}$. The relative humidity in the experimental chamber is maintained at about $80 \%$ so as to avoid evaporation and volume contraction of water droplet. The chemical composition of the wing surface is analyzed by means of FT-IR (Nicolet FT-IR200, USA). In the light of Cassie equation, a micro-morphological model for hydrophobicity on locust wing surface is established. Using SPSS 19.0 software, a nonlinear goodness-of-fit test between measured CAs and predicted CAs is carried out. Taking predicted CAs as independent variable $\mathrm{y}^{*}$, measured CAs as dependent variable $\mathrm{y}$, the degree of fitting is judged as follows:

$\mathrm{Q}=\sum(\mathrm{y}-\mathrm{y} *) 2$

$\mathrm{RNew}=1-\left(\mathrm{Q} / \sum \mathrm{y} 2\right) 1 / 2$

where $\mathrm{Q}$ is sum of square of deviations, $\mathrm{RNe}$ is the coefficient of determination in nonlinear regression equation. 


\section{RESULTS AND DISCUSSION}

\section{A. Chemical composition of the wing surface}

All the wings tested show extremely high similarity in the FT-IR spectra. For hind wings, the absorption peaks are at 3281, 2912, 2848, 1632, 1535, 1451, 1233, 1154, and $1069 \mathrm{~cm}-1$ (Fig. 1). The absorption band at $3281 \mathrm{~cm}-1$ results from stretching vibration of $\mathrm{O}-\mathrm{H}, \mathrm{N}-\mathrm{H}$ bases in alcohols, phenols, or carboxylic acid. The absorption bands at 2912, $2848 \mathrm{~cm}-1$ result from stretching vibration of $\mathrm{C}-\mathrm{H}$ base in protein, fat, or chitin. The absorption bands at 1632,1535, $1451 \mathrm{~cm}-1$ reveal benzene rings in locust wing. The absorption bands at $1233,1154,1069 \mathrm{~cm}-1$ arise from stretching vibration of $\mathrm{C}-\mathrm{O}$ base in functional groups such as acid anhydride, acyl chloride, ester, aldehyde, ketone, carboxy lic acid, acid amides. The results indicate locust wing is covered with a waxy layer composed mainly of long chain hydrocarbon, tallate and fatty-acid alcohol. Such a waxy layer, with an intrinsic CA of approximately $105^{\circ}$ [9], is the material coupling element for superhydrophobicity of locust wing surface.

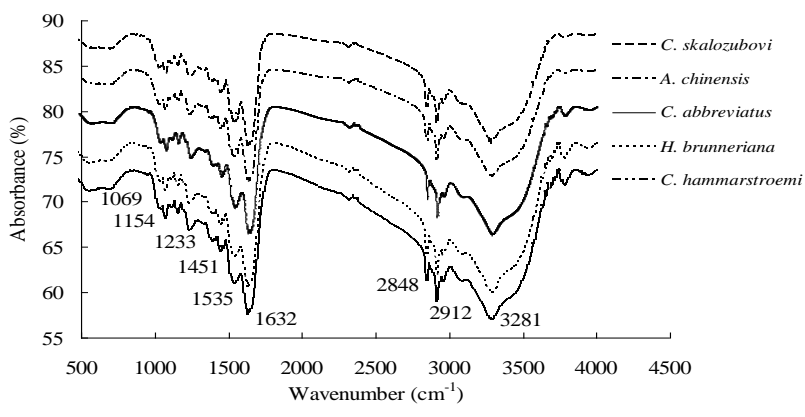

\section{B. Micro-morphology of the wing surface}

The five locust species have highly similar micromorphology of wing surface. The wing veins are very clear as grids, constituting the primary microstructure of wing surface [Fig. 2(a)]. The micrometric pillar gibbosities with uniform size distribute regularly and densely in the vein grids, constituting the secondary microstructure of wing surface [Fig. 2(b), 2(c)].

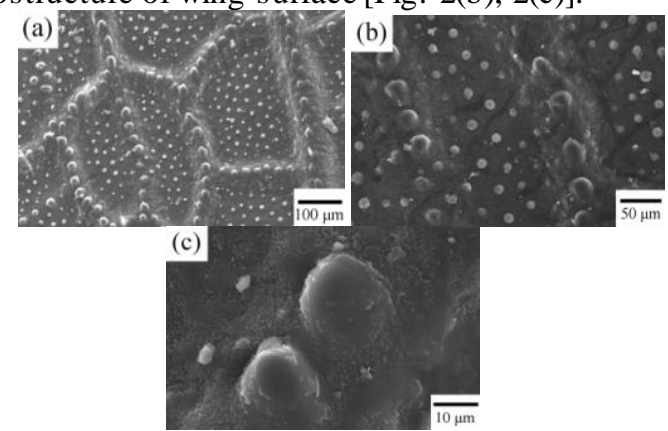

Figure 2. Rough micro-morphology of the locust wing surface (A. chinensis).

(a) primary microstructure (wing vein grids); (b) secondary microstructure (pillar gibbosities); (c) secondary microstructure (a single gibbosity) and tertiary microstructure (nano corrugat ions).

The diameter of gibbosity is $3.6 \sim 9.5 \mu \mathrm{m}$, the height is $4.1 \sim 8.6 \mu \mathrm{m}$, the space is $7.2 \sim 14.3 \mu \mathrm{m}$ (Table 1). The numerous nano corrugations between pillar gibbosities constitute the tertiary microstructure of wing surface [Fig. 2(c)].

Figure 1. The FT-IR spectra of the locust wing.

TABLE I. PARAMETERS OF MICRO-MORPHOLOGY (PILLAR GIBBOSITY) ON LOCUST WING SURFACE (MM) (MEAN \pm SD)

\begin{tabular}{|c|c|c|c|c|c|c|c|c|c|c|}
\hline \multirow[b]{2}{*}{ ra } & \multicolumn{2}{|c|}{ C. skalozubovi } & \multicolumn{2}{|c|}{ A. chinensis } & \multicolumn{2}{|c|}{ C. abbreviatus } & \multicolumn{4}{|c|}{ H. brunneriana C. hammarstroemi } \\
\hline & $\begin{array}{c}\text { Fore } \\
\text { wing }\end{array}$ & $\begin{array}{c}\text { Hind } \\
\text { wing }\end{array}$ & $\begin{array}{c}\text { Fore } \\
\text { wing }\end{array}$ & $\begin{array}{l}\text { Hind } \\
\text { wing }\end{array}$ & $\begin{array}{c}\text { Fore } \\
\text { wing }\end{array}$ & $\begin{array}{c}\text { Hind } \\
\text { wing }\end{array}$ & $\begin{array}{c}\text { Fore } \\
\text { wing }\end{array}$ & $\begin{array}{c}\text { Hind } \\
\text { wing }\end{array}$ & $\begin{array}{c}\text { Fore } \\
\text { wing }\end{array}$ & \\
\hline & & 1 & $2+0$ & $2+$ & & & & & 6 & $9 \pm 0$ \\
\hline & & & & & & & \pm 0.0 & $0.0 \pm 0.1$ & 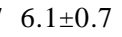 & 0.2 \\
\hline
\end{tabular}

\section{Superhydrophobicityof the wing surface}

All the CAs of water droplet on the wing surface of the five locust species are over $150^{\circ}$. The CAs of water droplet on fore wing and hind wing are 151.3 156.4 and $154.2 \sim 158.6^{\circ}$, respectively (Table 2), showing that locust wing surface is a natural bio-surface with superhydrophobicity. For the same locust species, hind wing's CA is larger than fore wing's CA, there is significant difference between them $(p<0.05)$. This accords with the functional differentiation of fore wing and hind wing in the process of co-evolution between locust and environment. The fore wing, which is narrow, tough and tensile, mainly takes charge of protection; while the hind wing, which is broad and soft, mainly taking charge of flying. The hind wing requires higher hydrophobicity and self-cleaning performance to reduce flying drag, lighten body burden, and improve movement efficiency.

TABLE II. MEASURED CAS AND PREDICTED CAS ON LOCUST WING SURFACE $\left(^{\circ}\right)($ MEAN \pm SD)

\begin{tabular}{|c|c|c|c|c|c|}
\hline \multirow{2}{*}{$\frac{\mathrm{CA}}{\text { Measured Fore wing }}$} & \multicolumn{5}{|c|}{ C. skalozubovi A. chinensis C. abbreviatus H. brunneriana C. hammarstroemi } \\
\hline & $153.4 \pm 4.0$ & $151.3 \pm 2.6$ & $153.6 \pm 2.7$ & $156.4 \pm 4.3$ & $152.6 \pm 3.5$ \\
\hline Hind wing & $\quad 155.2 \pm 3.5$ & $154.7 \pm 3.3$ & $155.7 \pm 2.9$ & $158.6 \pm 4.1$ & $154.2 \pm 4.2$ \\
\hline Predicted Fore wing & $155.6 \pm 3.9$ & $153.4 \pm 3.8$ & $152.3 \pm 3.1$ & $158.2 \pm 4.2$ & $155.0 \pm 3.8$ \\
\hline Hind wing & $157.5 \pm 4.4$ & $157.2 \pm 4.9$ & $156.5 \pm 4.3$ & $162.3 \pm 5.4$ & $157.1 \pm 4.7$ \\
\hline
\end{tabular}

The diameter of a water droplet is about $2.1 \mathrm{~mm}$, far outweighing the spacing $(7.2 \sim 14.3 \mu \mathrm{m})$ of pillar gibbosity. The droplet can neither enter totally the grooves between gibbosities, nor contact fully with the 
wing surface. A gas film exists stably between droplet and wing surface. A composite contact occurs, exhibiting a larger CA. Owing to the chemical composition (waxy layer), locust wing surface can achieve hydrophobicity (CA 105 $)$ [9]. The superhydrophobicity (water CA over $150^{\circ}$ ) results from the coupling of naturally hydrophobic material and multiple-dimensional rough microstructure.

\section{A micro-morphological model for hydrophobicity of the wing surface}

Young proposed an equation for contact state of a droplet on an ideal (flat, smooth) solid surface while balancing:

$$
\cos \theta=\frac{\gamma_{\mathrm{SV}}-\gamma_{\mathrm{SL}}}{\gamma_{\mathrm{LV}}}
$$

where $\theta$ is the apparent CA of a droplet on a solid surface, $\gamma_{\mathrm{SV}}, \gamma_{\mathrm{SL}}$, and $\gamma_{\mathrm{LV}}$ are the interface tensions of solid-vapor interface, solid-liquid interface, and liquid-vapor interface, respectively. The solid surface in reality, nevertheless, which is not an ideal one. On the basis of Young's equation, Cassie and Baxter put forward a model to describe the relationship between the apparent $\mathrm{CA}(\theta \mathrm{c})$ and the intrinsic $\mathrm{CA}(\theta \mathrm{e})$ when a composite contact is formed between a droplet and a rough surface:

(2)

$$
\cos \theta_{\mathrm{c}}=\phi_{\mathrm{s}}\left(1+\cos \theta_{\mathrm{e}}\right)-1
$$

\section{where $\phi_{\mathrm{s}}$ is the area fraction of liquid/solid contact $\left(0<\phi_{\mathrm{s}}<1\right)$. A micro-morphological model for} hydrophobicity on locust wing surface is shown in Fig. 3.

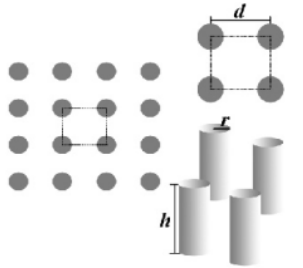

Figure 3. A micro-morphological model for hydrophobicity on the rough surface of locust wing.

The parameters $\mathrm{r}, \mathrm{h}$, and $\mathrm{d}$ represent radius, height, and spacing of pillar gibbosity, respectively. Thus,

$$
\phi_{\mathrm{s}}=\pi r^{2} / d^{2}
$$

$\theta \mathrm{c}$ is determined by $\mathrm{r}$ and $\mathrm{d}$, has nothing to do with $\mathrm{h}$. This is because the droplet does not fill up the rough microstructure completely in a composite contact. As the $\mathrm{h}$ is bigger, the droplet is more difficult to enter the groove; conversely, in the case of smaller $\mathrm{h}$ and larger $\mathrm{d}$, the droplet is easier to transit from "Cassie state" with higher energy to "Wenzel state" with lower energy[10].

The main component of locust wing surface is waxy crystal with an intrinsic CA $(\theta e)$ of $105^{\circ}$ [9]. The values of $r$ and $d$ can be obtained from the micro-morphological parameters on the wing surface (Table 1). $\phi_{\mathrm{s}}$ can be calculated and substituted into Equation (2), then the predicted CA $(\theta \mathrm{c})$ can be calculated (Table 2). According to the result of nonlinear goodness-of-fit test between the predicted CAs and the measured CAs, the RNew values (coefficients of determination) are 0.948 0.975 for fore wing, 0.942 0.971 for hind wing (Table 3). There is no significant difference between the measured CAs and the predicted CAs. The degree of fitting is fine. The micro-morphological model for

\begin{tabular}{|c|c|c|c|c|c|c|c|c|c|c|}
\hline Species & C. skal & zubovi & A.ch & ensis & C. $a b b$ & eviatus & H. brun & eriana & C. hamma & stroemi \\
\hline Wing & $\begin{array}{c}\text { Fore } \\
\text { wing }\end{array}$ & $\begin{array}{l}\text { Hind } \\
\text { wing }\end{array}$ & $\begin{array}{c}\text { Fore } \\
\text { wing }\end{array}$ & $\begin{array}{l}\text { Hind } \\
\text { wing }\end{array}$ & $\begin{array}{c}\text { Fore } \\
\text { wing }\end{array}$ & $\begin{array}{l}\text { Hind } \\
\text { wing }\end{array}$ & $\begin{array}{c}\text { Fore } \\
\text { wing }\end{array}$ & $\begin{array}{l}\text { Hind } \\
\text { wing }\end{array}$ & Fore wing & $\begin{array}{l}\text { Hind } \\
\text { wing }\end{array}$ \\
\hline$R_{\text {New }}$ & 0.965 & 0.947 & 0.948 & 0.942 & 0.951 & 0.971 & 0.975 & 0.962 & 0.954 & 0.963 \\
\hline
\end{tabular}
hydrophobicity is in good accord with Cassie equation.

TABLE III. NONLINEAR GOODNESS-OF-FIT TEST BETWEEN PREDICTED CA AND MEASURED CA ON LOCUST WING (RNEW)

IV. CONCLUSIONS

Locust wing surface is a waxy layer composed mainly of long chain hydrocarbon, tallate and fatty-acid alcohol. The wing surface possesses multipledimensional rough microstructures. Wing vein grids comprise the primary microstructure. The micrometric pillar gibbosities arraying regularly in the grids comprise the secondary microstructure. The numerous nano corrugations comprise the tertiary microstructure. A composite contact occurs between droplet and locust wing. Locust wing is a natural bio-surface with superhydrophobicity (water CA 151.3 158.6 ${ }^{\circ}$ ). The micro-morphological model for hydrophobicity of locust wing surface established is in good accord with Cassie equation. The degree of fitting between predicted CAs and measured CAs is fine. The superhydrophobic property of locust wing surface is attributed to cooperate the effect of material coupling element (waxy crystal) and structure coupling element (hierarchical rough microstructure). Locust wing can be potentially used as a biomimetic template for design of functional surface with special wettability. This work promotes the understanding of superhydrophobicity on bio-surfaces, and may bring interesting insights for preparation of micro-controllable superhydrophobic surface.

\section{ACKNOWLEDGMENTS}

This work was financially supported by the National Natural Science Foundation of China (50875108), the Natural Science Foundation of Jilin Province, China (201115162), Science and Technology Project of Educational Department of Jilin Province, China (2009210, 2010373, 2011186).

\section{REFERENCES}

[1] S.T. Wang, L. Jiang, Definition of superhydrophobic states, Adv. Mater.19,3423 (2007).

[2] S. Yang, J. Ju, Y.C. Qiu et al, Superhydrophobic materials: peanut leaf inspired multifunctional surfaces, Small10,214 (2014). 
[3] B. Bhushan, E.K. Her, Fabrication of superhydrophobic surfaces with high and low adhesion inspired from rose petal, Langmuir26,8207 (2010).

[4] X.J. Wang, Q. Cong, J.J. Zhang et al., Multivariate coupling mechanism of NOCTUIDAE moth wings' surface superhydrophobicity, Chin. Sci. Bull.54,569(2009).

[5] M.H. Jin, X.J. Feng, L. Feng et al., Superhydrophobic aligned polystyrene nanotube films with high adhesive force, Adv. Mater.17,1977 (2005)

[6] G. Sun, Y. Fang, Q. Cong et al., Anisotropism of the nonsmooth surface on butterfly wing, J. Bionic Eng.6,71 (2009).
[7] Y. Fang, G. Sun, Q. Cong, Effects of methanol on wettability of the non-smooth surface on butterfly wing, J. Bionic Eng.5,127 (2008).

[8] Y. Fang, G. Sun, T.Q. Wang et al., Hydrophobicity mechanism of non-smooth pattern on surface of butterfly wing, Chin. Sci. Bull.52,711 (2007).

[9] Y. Fang, G. Sun, Y.H. Bi et al., Multiple-dimensional micro/nano structural models for hydrophobicity of butterfly wing surfaces and coupling mechanism, Science Bulletin60,256 (2015).

[10] N.A. Patankar, On the modeling of hydrophobic contact angles on rough surfaces, Langmuir 19,1249(2003). 